\title{
PENENTUAN JUMLAH TENAGA KERJA DENGAN \\ MENGGUNAKAN SIMULASI ANTRIAN DI DEPARTEMEN PRODUKSI \\ DI PT. SURYA TUBAL INDONESIA
}

\author{
Murti Astuti ${ }^{1}$ Ilyas Mas'udin ${ }^{2}$
}

\begin{abstract}
In its production process, a company is consisted of various departments supporting one another in a good teamwork to build a single unity. Therefore inefficiency in one of those departments will affect other departments that in turn will have impact on production outcome. One of those departments is production department that is one of the most important sections which plays important role in production smoothness.

One of problems disturbing the smoothness of flow process in this department is the problem of long product lining marked by considerable waiting time. This is certainly ineffective since it will not only disturb the production process flow but also decrease the product quality caused by too much waiting time in the line. Therefore, we have to make an effort in reducing the line size while still consider the cost just in case an improvement is made. To overcome this matter, one way we could take is utilizing a line simulation by optimizing service facilities number (number of labor force) with minimum cost and product waiting time.
\end{abstract}

Keywords : line, server, waiting time.

\section{PENDAHULUAN}

Perusahaan merupakan sebuah sistem yang terdiri atas sub-sub sistem yang sangat kompleks dengan tujuan akhir keuntungan sebesar-besarnya dengan menciptakan sistem produktif, efisien dan murah. Produktifitas dan efisiensi sistem akan meningkat bila subsub sistem yang ada juga berjalan dengan baik dan begitu pula sebaiknya.

Salah satu sub sistem dari proses produksi di perusahaan adalah departemen produksi yang merupakan salah satu rute penting yang harus dilalui dalam proses produksi yang diambil sebagai pokok bahasan penelitian. Bagian ini juga sangat berperan karena bagian ini juga ikut menentukan tingkat kualitas produk.

Antrian yang terjadi disebabkan karena penempatan jumlah tenaga kerja yang kurang optimal dengan kondisi yang ada sehingga aktivitas yang dilakukan tidak efektif sehingga akan berpengaruh terhadap biaya produksi. Salah satu metode atau cara untuk mengatasi hal tersebut dengan menggunakan teori antrian yang disimulasikan dengan menggunakan bantuan software Arena.

\section{TINJAUAN PUSTAKA}

Proses dasar antrian adalah adanya pelanggan atau customer atau produk datang baik dengan laju tetap atau tidak dari sumber input yang membutuhkan pelayanan server, bila mereka tidak dapat masuk ke fasilitas pelayanan 
maka pelanggan harus menunggu hingga membentuk antrian.

Struktur dasar antrian bisa berbentuk: Single Chanel-Single Operation, Single Chanel-Multiple Operation, Multiple Chanel-Single Operation, Multiple Chanel-Multiple Operation. Sementara sistem antrian yang kompleks membutuhkan analisa menggunakan simulasi.

\section{Disiplin Antrian}

Merupakan suatu kebijakan bagaimana cara pelanggan dipilih dan dilayani antara lain:

> First In First Out (datang pertama akan dilayani pertama)

> Last In Last Out (pelanggan datang terakhir akan dilayani pertama)

$>$ Service In Random Order (pelanggan dilakukan secara acak

$>$ Priority Service (pelayanan dilakukan dengan tingkatan prioritas pelanggan)

\section{Distribusi Kedatangan}

Pertibaan dari n satuan secara acak

$$
P n(t)=\frac{(\lambda t)^{n} \cdot e^{-\lambda t}}{1 !}, n \geq 0, t \geq 0
$$

dalam antrian pada waktu $t$, yaitu:

(P.Siagian 1987 : 400)

yang merupakan distribusi Poisson.

\section{Distribusi Pelayanan}

Waktu pelayanan akan memnuhi suatu distribusi Eksponensial dengan parameter $\mu$ :

$$
P n(t)=\frac{(\mu t)^{M-n} \cdot e^{\mu \lambda t}}{(M-n) !}
$$

\section{Model Biaya Optimum}

Model biaya dalam antrian berusaha menyeimbangkan biaya menunggu dengan biaya kenaikan tingkat pelayanan, komponen penting dari kedua biaya itu adalah:

* Biaya menunggu (Waiting Cost)

* Biaya pelayanan

Sementara jumlah pelayanan (c) optimum dapat diperoleh :

$\mathrm{ETC}_{(\mathrm{c})}=\mathrm{EOC}_{(\mathrm{s})}+\mathrm{EWC}_{(\mathrm{s})}$

Dimana :

$\mathrm{EOC}=$ Biaya operasi sarana perunit

$\mathrm{EWC}=$ Biaya menunggu perunit waktu

$\mathrm{C}=$ Jumlah Pelayanan pararel

Nilai optimum $\mathrm{c}$ harus memenuhi kondidi yang diperlukan berikut:

$\mathrm{ETC}_{(\mathrm{c}-1)} \geq \mathrm{ETC}_{(\mathrm{c})}$ dan $\mathrm{ETC}_{(\mathrm{c}+1)} \geq \mathrm{ETC}_{(\mathrm{c})}$

Sebagai aplikasi dari kondidi ini maka dapat dipertimbangkan fungsi biaya sbb:

$\mathrm{EOC}_{(\mathrm{c})}=\mathrm{C} 1 \cdot \mathrm{c}$

$\mathrm{EWC}_{(\mathrm{c})}=\mathrm{C} 2 \cdot \mathrm{Ls}(\mathrm{c})$

Sehingga $\mathrm{TC}_{(\mathrm{c})}=\mathrm{c} . \mathrm{C} 1+\mathrm{C} 2 . \mathrm{W}_{(\mathrm{c})}$

Dimana:

$\mathrm{C} 1$ : biaya perpelanggan tambahan perunit waktu

$\mathrm{C} 2$ : biaya perunit waktu menunggu pelanggan

W : Jumlah pelanggan yang diperkirakan dalam sistem dengan diketahui $\mathrm{c}$ 
Dengan menerapkan kondisi yang diperlukan kita peroleh:

$\mathrm{E}_{\mathrm{c}}(\mathrm{nt})-\mathrm{E}_{\mathrm{c}+1}(\mathrm{nt}) \leq \mathrm{C} 1 / \mathrm{C} 2 \leq \mathrm{E}_{\mathrm{c}-1}(\mathrm{nt})-\mathrm{E}_{\mathrm{c}}(\mathrm{nt})$

Nilai $\mathrm{C} 1 / \mathrm{C} 2$ menunjukkan dimana pencarian untuk $\mathrm{c}$ optimal harus dimulai.

\section{Simulasi Sistem}

Ada beberapa alasan penggunaan simulasi antara lain:

- Sistem real sangat kompleks bila direpresentasikan dengan model analitis

- Model analitis dapat disusun tetapi sangat sulut dipecahkan

- Eksperimentasi langsung di dunia nyata sangat mahal, membutuhkan waktu yang banyak dan sangat berbahayaterhadap sistem itu sendiri bila mengalami kegagalan.

\section{Keuntungan Simulasi}

* Simulasi memungkinkan pelaksanaan pengamatan dan pengujian analitis terhadap sistem nyata yang kompleks dan berelemen stochastic

* Simulasi memudahkan pengamat untuk mengestimasi kinerja sistem yang ada dengan sekumpulan kondisi opersi

* Alternatif rancangan sistem dapat dibandingkan dengan simulasi untuk memperoleh yang terbaik dan relevan dengan kebutuhan yang diinginkan
* Simulasi memudahkan pelaksanaan perbaikan dan perubahan yang masih dalam kondisi percobaan.

* Simulasi dapat memberikan penelusuran sistem dalam jangka waktu lama dengan pengamatan yang relatif jauh lebih pendek.

\section{Langkah Perancangan Simulasi}

1. Perumusan Masalah dan perencanaan masalah

2. Pengumpulan data dan pendefinisian model

3. Pengujian validasi

4. Perancangan dan verifikasi program komputer

5. Percobaan menjalankan program komputer untuk mendapatkan hasil yang akan diuji kessesuaiannya dengan sistem

6. Pengujian validasi

7. Design eksperimen

8. Pelaksanaan menjalankan program komputer (production Run)

9. Analisa hasil keluaran.

\section{METODOLOGI PENELITIAN}

Dari survey pada PT. Surya Tubal yang merupakan produsen "pasta" dirumuskan tujuan dan langkah-langkah penelitian yang dimulai dari identifikasi data yang diperlukan seperti waktu kedatangan (arrival time), waktu pelayanan (service time), jumlah server serta data biaya (cost) baik langsung maupun tak langsung.

Kemudian dilakukan pengolahan data berupa pendugaan distribusi arrival time dan service time dan dilakukan pengujian distribusi 
menggunakan uji kolmogorov-smirnov dengan alat bantu statgraphics.

Langkah selanjutnya adalah pem-buatan model antrian real untuk melihat kondisi sebenarnya sebelum dilakukan perbaikan. Setelah itu dilakukan analisa antrian dengan menggunakan teori antrian dengan membuat usulan-usulan berupa skenario model dengan menggunakan alat bantu software simulasi Arena kemudian dilakukan perbandingan biaya dan waktu tunggu yang minimal.

\section{HASIL DAN PEMBAHASAN}

Dari data yang didapatkan yaitu waktu kedatangan dan waktu pelayanan di setiap workstation proses produksi departemen produksi masing-masing dilakukan uji distrbusi untuk menentukan jenis distribusinya dengan alat bantu statgraphics menggunakan uji Kolmogorov-Smirnov $(\alpha=0,05)$ dengan Ho dapat diterima bila DN Hitung $<$ DN tabel:

\section{Tabel 1}

\section{Hasil Uji Distribusi}

\begin{tabular}{|c|c|c|c|}
\hline Workstation & DN & $\begin{array}{c}\text { DN, } \\
\mathbf{9 5 \%}\end{array}$ & Kesimpulan \\
\hline Kedatangan 1 & 0.074 & 0.242 & Eksponensial \\
\hline Kedatangan 2 & 0.095 & 0.224 & Eksponensial \\
\hline Kedatangan 3 & 0.146 & 0.242 & Eksponensial \\
\hline $\begin{array}{c}\text { Pelayanan } \\
\text { Pressing 1 }\end{array}$ & 0.155 & 0.242 & Eksponensial \\
\hline $\begin{array}{c}\text { Pelayanan } \\
\text { Pressing 2 }\end{array}$ & 0.124 & 0.224 & Eksponensial \\
\hline $\begin{array}{c}\text { Pelayanan } \\
\text { Pressing 3 }\end{array}$ & 0.112 & 0.294 & Eksponensial \\
\hline $\begin{array}{c}\text { Pelayanan } \\
\text { Packing 1 }\end{array}$ & 0.163 & 0.294 & Eksponensial \\
\hline $\begin{array}{c}\text { Pelayanan } \\
\text { Oven 1 }\end{array}$ & 0.137 & 0.294 & Eksponensial \\
\hline
\end{tabular}

\begin{tabular}{|c|c|c|c|}
\hline Workstation & DN & $\begin{array}{l}\text { DN, } \\
95 \%\end{array}$ & Kesimpulan \\
\hline $\begin{array}{l}\text { Pelayanan } \\
\text { Inspeksi } 1\end{array}$ & 0.144 & 0.294 & Eksponensial \\
\hline $\begin{array}{c}\text { Pelayanan } \\
\text { Spray } 1\end{array}$ & 0.012 & 0.242 & Eksponensial \\
\hline $\begin{array}{c}\text { Pelayanan } \\
\text { Spray } 2\end{array}$ & 0.118 & 0.294 & Eksponensial \\
\hline $\begin{array}{c}\text { Pelayanan } \\
\text { Spray } 3\end{array}$ & 0.143 & 0.294 & Eksponensial \\
\hline $\begin{array}{c}\text { Pclayanan } \\
\text { Oven } 2\end{array}$ & 0.103 & 0.242 & Eksponensial \\
\hline $\begin{array}{c}\text { Pelayanan } \\
\text { Oven } 3\end{array}$ & 0.132 & 0.264 & Eksponensial \\
\hline $\begin{array}{l}\text { Pelayanan } \\
\text { Inspeksi } 2\end{array}$ & 0.116 & 0.264 & Eksponensial \\
\hline $\begin{array}{c}\text { Kedatangan } \\
\text { Packing } 1\end{array}$ & 0.100 & 0.242 & Eksponensial \\
\hline $\begin{array}{c}\text { Kedatangan } \\
\text { Oven } 1\end{array}$ & 0.158 & 0.242 & Eksponensial \\
\hline $\begin{array}{c}\text { Kedatangan } \\
\text { Inspeksi } 1\end{array}$ & 0.191 & 0.242 & Eksponensial \\
\hline $\begin{array}{c}\text { Kedatangan } \\
\text { Spray } 1\end{array}$ & 0.106 & 0.242 & Eksponensial \\
\hline $\begin{array}{c}\text { Kedatangan } \\
\text { Spray } 2\end{array}$ & 0.115 & 0.294 & Eksponensial \\
\hline $\begin{array}{c}\text { Kedatangan } \\
\text { Spray } 3\end{array}$ & 0.149 & 0.242 & Eksponensial \\
\hline $\begin{array}{c}\text { Kedatangan } \\
\text { Oven } 2\end{array}$ & 0.113 & 0.210 & Eksponensial \\
\hline $\begin{array}{c}\text { Kedatangan } \\
\text { Oven } 3\end{array}$ & 0.089 & 0.242 & Eksponensial \\
\hline $\begin{array}{c}\text { Kedatangan } \\
\text { Inspeksi } 2\end{array}$ & 0.180 & 0.242 & Eksponensial \\
\hline
\end{tabular}

Dari hasil uji distribusi di setiap station dapat disimpulkan bahwa distribusi kedatangan dan pelayanan berdistribusi Eksponensial.

\section{Analisa Antrian}

Dari hasil pengolahan didapatkan parameter antrian berupa rate kedatangan dan pelayanan sebagai berikut:

Tabel 2

\section{Parameter Antrian}

\begin{tabular}{|l|c|c|c|}
\hline Worstation & $\mu$ (menit) & $\lambda$ (menit) & $\rho$ \\
\hline Pressing 1 & 0.364 & 034 & 0.93 \\
\hline Pressing 2 & 0.37 & 0.550 & 1.49 \\
\hline Pressing 3 & 3.056 & 0.50 & 1.5 \\
\hline Packing 1 & 0.123 & 0.45 & 3.67 \\
\hline Oven 1 & 0.197 & 0.198 & 1.01 \\
\hline Inspeksi 1 & 0.197 & 0.96 & 0.88 \\
\hline Spray 1 & 0.33 & 0.41 & 1.22 \\
\hline Spray 2 & 0.32 & 0.396 & 1.22 \\
\hline Spray 3 & 0.245 & 0.61 & 2.5 \\
\hline Oven 2 & 0.35 & 0.34 & 0.97 \\
\hline Oven 3 & 0.35 & 0.32 & 0.92 \\
\hline Inspeksi 2 & 0.45 & 1.09 & 2.42 \\
\hline
\end{tabular}


Dari tabel dapat dilihat bahwa packing , oven 1 dan inspeksi 2 mempunyai nilai $\rho$ $>1$ sehingga terjadi antrian, untuk itu dicoba penambahan/tenaga kerja untuk mengurangi jumlah antrian. Dalam hal ini penambahan server disesuaikan dengan kemampuan perusahaan saat ini.

Dengan menggunakan model keputusan yang bertujuan mencari jumlah server (c) optimum di tiap bagian departemen produksi dimana cost tambahan tiap server per satuan waktu $(\mathrm{C} 1)=\mathrm{Rp} .7 .500 /$ hari dan waiting cost produk per satuan waktu $=$ Rp. 300.000 sehingga dengan menggunakan rumus $\mathrm{Ec}(\mathrm{nt})-\mathrm{Ec}+1(\mathrm{nt})<=\mathrm{Ec}-1(\mathrm{nt})-\mathrm{Ec}(\mathrm{nt})$, dimana harga $\mathrm{C} 1 / \mathrm{C} 2$ memberikan petunjuk ke arah mana pencarian harga c optimum dimulai. Sedangkan Ec(nt) didapatkan dari rumus:

$$
E n t=f b\left[\frac{\lambda}{c \cdot \mu-\lambda}\right]+\frac{\lambda}{\mu}
$$

\section{Pembuatan Skenario}

Skenario dibuat untuk mengetahui dan menentukan sistem terbaik dari semua alternatif usulan yang bisa diterapkan. Disini ada 4 skenario (dengan batasan tertentu) yang disiapkan untuk mencari solusi optimal. Dengan bantuan software simulasi Arena skenario-skenario tersebut menghasilkan:
Tabel 3

\section{Waktu Tunggu Rata-rata}

\begin{tabular}{|l|c|c|c|c|}
\hline Station & \multicolumn{4}{|l|}{ Waktu Tunggu Rata-rata (menit) } \\
\cline { 2 - 5 } & $\begin{array}{l}\text { Ske- } \\
\text { nario 1 }\end{array}$ & $\begin{array}{l}\text { Ske- } \\
\text { nario 2 }\end{array}$ & $\begin{array}{l}\text { Sken- } \\
\text { ario 3 }\end{array}$ & $\begin{array}{l}\text { Sken- } \\
\text { ario 4 }\end{array}$ \\
\hline $\begin{array}{l}\text { Packing } \\
\text { 1 }\end{array}$ & 130,79 & 80,2 & 50,41 & 138,68 \\
\hline Oven 1 & 0,00 & 0,00 & 0,00 & 0,00 \\
\hline $\begin{array}{l}\text { Inspeksi } \\
\text { 1 }\end{array}$ & 0,06 & 0,111 & 0,228 & 0,08 \\
\hline Oven 2 & 0,00 & 0,00 & 0,00 & 0,00 \\
\hline Oven 3 & 0,00 & 0,00 & 0,327 & 0,02 \\
\hline $\begin{array}{l}\text { Inspeksi } \\
\text { 2 }\end{array}$ & 0,04 & 0,00 & 0,22 & 0,377 \\
\hline
\end{tabular}

\section{Pembahasan dan Hasil}

Dari keempat skenario yang dibuat dengan bantuan software simulasi Arena didapatkan total cost sebagai berikut:

Tabel 4

Skenario 1

\begin{tabular}{|c|c|c|}
\hline Station & $\begin{array}{c}\text { Jumlah Tenaga } \\
\text { Kerja }\end{array}$ & $\begin{array}{c}\text { Total Cost } \\
\text { (Rp.) }\end{array}$ \\
\hline Packing 1 & 2 & 708.950 \\
\hline Oven 1 & 6 & 125.000 \\
\hline Inspeksi 1 & 6 & 85.300 \\
\hline Oven 2 & 2 & 95.000 \\
\hline Oven 3 & 2 & 95.000 \\
\hline Inspeksi 2 & 6 & 85.200 \\
\hline
\end{tabular}

Tabel 5

Skenario 2

\begin{tabular}{|l|c|c|}
\hline Station & $\begin{array}{c}\text { Jumlah } \\
\text { Tenaga Keria }\end{array}$ & $\begin{array}{c}\text { Total Cost } \\
\text { (Rp.) }\end{array}$ \\
\hline Packing 1 & 4 & 470.000 \\
\hline Oven 1 & 6 & 125.000 \\
\hline Inspeksi 1 & 6 & 85.555 \\
\hline Oven 2 & 2 & 95.000 \\
\hline Oven 3 & 2 & 95.000 \\
\hline Inspeksi 2 & 6 & 85.000 \\
\hline
\end{tabular}

Tabel 6

Skenario 3

\begin{tabular}{|l|c|c|}
\hline Station & $\begin{array}{c}\text { Jumlah } \\
\text { Tenaga Kerja }\end{array}$ & $\begin{array}{c}\text { Total Cost } \\
(\mathbf{R p .})\end{array}$ \\
\hline Packing 1 & 6 & 33.050 \\
\hline Oven 1 & 6 & 125.000 \\
\hline Inspeksi 1 & 6 & 86.140 \\
\hline Oven 2 & 2 & 95.000 \\
\hline Oven 3 & 2 & $96.633,75$ \\
\hline Inspeksi 2 & 6 & 86.100 \\
\hline
\end{tabular}


Tabel 7

Skenario 4

\begin{tabular}{|l|c|c|}
\hline \multicolumn{1}{|c|}{ Station } & $\begin{array}{c}\text { Jumlah } \\
\text { Tenaga } \\
\text { Kerja }\end{array}$ & $\begin{array}{c}\text { Total Cost } \\
\text { (Rp.) }\end{array}$ \\
\hline Packing 1 & 2 & 748.400 \\
\hline Oven 1 & 2 & 95.000 \\
\hline Inspeksi 1 & 6 & 85.400 \\
\hline Oven 2 & 2 & 95.000 \\
\hline Oven 3 & 2 & $95.096,8$ \\
\hline Inspeksi 2 & 2 & 56.834 \\
\hline
\end{tabular}

\section{KESIMPULAN}

Dari pengolahan dan analisa dengan menggunakan metode simulasi antrian maka didapatkan:

$>$ Jumlah total fasilitas pelayanaan (tenaga kerja) di departemen produksi yang optimal (sesuai skenario 3) adalah 28 orang

> Waktu total tunggu (waiting time) sebesar 51,185 menit Total cost yang harus dikeluarkan perusahaan sebesar Rp. 825.923 .

Dibandingkan kondisi awal :

$>$ Jumlah total fasilitas pelayanan 16 orang

> Total waktu tunggu 139,146 menit. Dengan cost yang harus dikeluarkan sebesar Rp. 1.175.730,8

\section{DAFTAR PUSTAKA}

P. Siagian, 1987, Penelitian Operasional. Teori dan Praktek, UI-Press.

Kelton David, W. And Sadowski, P. Randall, 1998, Simulation With Arena. McGrawHill.

Kleinrock, Leonard. 1975 Queueing Syatem, John Willey \& Sons, New York.

Law, Averill M. And W. David Kelton, 1991, Simulation Modeling and Analysis. McGraw-Hill Book Co. New York.

Walphole,1995, Pengantar Statistik, Gramedia, Jakarta.

Siegel,1995, Statistik Non Parametrik untuk

Ilmu-Ilmu Sosial, Gramedia, Jakarta.

Wignjosoebroto, Sritomo,1995, Ergonomi

Study Gerak dan Waktu. PT. Guna Widya. 